\title{
Arginine methylation-dependent regulation of ASK1 signaling by PRMT1
}

\author{
J-H Cho ${ }^{1}$, M-K Lee ${ }^{1}$, KW Yoon ${ }^{1}$, J Lee ${ }^{1}$, S-G Cho ${ }^{2}$ and E-J Choi ${ }^{*, 1,3}$
}

Protein arginine methylation, catalyzed by protein arginine methyltransferases (PRMTs), is implicated in modulation of cellular processes including gene transcription. The role of PRMTs in the regulation of intracellular signaling pathways has remained obscure, however. We now show that PRMT1 methylates apoptosis signal-regulating kinase 1 (ASK1) at arginine residues 78 and 80 and thereby negatively regulates ASK1 signaling. PRMT1-mediated ASK1 methylation attenuated the $\mathrm{H}_{2} \mathrm{O}_{2}$-induced stimulation of ASK1, with this inhibitory effect of PRMT1 being abolished by replacement of arginines 78 and 80 of ASK1 with lysine. Furthermore, depletion of PRMT1 expression by RNA interference potentiated $\mathrm{H}_{2} \mathrm{O}_{2}$-induced stimulation of ASK1. PRMT1mediated ASK1 methylation promoted the interaction between ASK1 and its negative regulator thioredoxin, whereas it abrogated the association of ASK1 with its positive regulator TRAF2. Moreover, PRMT1 depletion potentiated paclitaxel-induced ASK1 activation and apoptosis in human breast cancer cells. Together, our results indicate that arginine methylation of ASK1 by PRMT1 contributes to the regulation of stress-induced signaling that controls a variety of cellular events including apoptosis. Cell Death and Differentiation (2012) 19, 859-870; doi:10.1038/cdd.2011.168; published online 18 November 2011

Apoptosis signal-regulating kinase 1 (ASK1) is a mitogenactivated protein (MAP) kinase kinase kinase (MAP3K) that contributes to stress-activated MAP kinase signaling pathways, including those mediated by c-Jun $\mathrm{NH}_{2}$-terminal kinase (JNK) and p38 pathways, by catalyzing the phosphorylation of MAP kinase kinase (MAP2K). ASK1 thereby has a key role in cellular responses to various types of stress, including oxidative stress, ER stress, calcium overload and exposure to TNF- $\alpha$ or bacterial endotoxin. ${ }^{1,2}$ The sustained operation of these stress-activated pathways eventually results in the induction of apoptosis through mitochondrion-dependent caspase activation. ${ }^{3}$ In addition to the induction of apoptosis as a result of its persistent activation, ${ }^{4,5}$ ASK1 has been shown to participate in the regulation of a variety of biological events, including cell differentiation and the innate immune response. ${ }^{1,2}$ Furthermore, ASK1 has been implicated in the pathogenesis of human disorders such as neurodegenerative diseases, ischemia-reperfusion injury, cardiovascular diseases, chronic inflammation, and diabetes mellitus. ${ }^{1,2}$

The kinase activity of ASK 1 is regulated by posttranslational modifications such as phosphorylation and S-nitrosylation. ${ }^{6-8}$ It is also modulated by ASK1-interacting proteins: thioredoxin, p21, glutathione S-transferase $\mu, \mathrm{Hsp} 72$, and CIIA thus negatively regulate ASK1, whereas Daxx and AIP1 positively regulate ASK1 activity. $^{9-14}$ Thioredoxin, the first identified ASK1-interacting protein, is a thiol-redox-sensitive protein and has a critical role in the mechanism of ASK1 activation by reactive oxygen species (ROS). ${ }^{15}$ ASK1 contains a kinase domain in the central region and two coiled-coil domains in the $\mathrm{NH}_{2^{-}}$and $\mathrm{COOH}$-terminal regions. ${ }^{2}$ In unstimulated states, the inactive ASK1 forms a homo-oligomer through the $\mathrm{COOH}$ terminal coiled-coil (CCC) domain and a heteromeric interaction with the reduced form of thioredoxin through its $\mathrm{NH}_{2}$-terminal region. Upon ROS-induced oxidation of thioredoxin, ASK1 is released from the oxidized thioredoxin and associates with TNF receptor-associated factor 2 (TRAF2) or TRAF6. TRAF2 or TRAF6 promotes the homophilic interaction of the $\mathrm{NH}_{2}$-terminal coiled-coil (NCC) domain of ASK1, thereby facilitating the formation of active ASK1 complex. This homo-oligomerization of ASK1 through the NCC domain is essential for ROS-induced ASK1 activation. ${ }^{16-18}$

Protein arginine methyltransferases (PRMTs) catalyze protein arginine methylation, a posttranslational modification conserved among many eukaryotes, by transferring a methyl group from S-adenosyl-L-methionine (SAM) to the guanidino group of arginine. ${ }^{19,20}$ PRMTs are classified as type I or type II on the basis of the nature of the modification of their substrates. Although both types catalyze the formation of monomethylarginine as an intermediate, type I enzymes mediate the formation of asymmetric dimethylarginine, whereas type II enzymes produce symmetric dimethylarginine. ${ }^{19,21}$ Type I enzymes include PRMT1, PRMT3, PRMT4, PRMT6, and PRMT8, whereas type II enzymes include PRMT5, PRMT7, and FBXO11. Arginine methylation does not affect the positive charge of the arginine residue. It does, however, increase steric hindrance as a result of the addition

\footnotetext{
${ }^{1}$ School of Life Sciences and Biotechnology, Korea University, Seoul 136-701, Korea; ${ }^{2}$ Department of Animal Biotechnology, Konkuk University, Seoul 143-701, Korea and ${ }^{3}$ School of Pharmacy, Korea University, Yeongi, Chungnam 339-700, Korea

*Corresponding author: E-J Choi, School of Life Sciences and Biotechnology, Korea University, Seoul 136-701, Korea. Tel: + 82232903446 ; Fax: + 82 2 3290 4741; E-mail: ejchoi@korea.ac.kr

Keywords: arginine methylation; ASK1; paclitaxel; PRMT1

Abbreviations: AdOx, adenosine dialdehyde; ASK1, apoptosis signal-regulating kinase 1; CCC, COOH-terminal coiled-coil; GFP, green fluorescence protein; $\mathrm{HA}$, hemagglutinin; JNK, c-Jun $\mathrm{NH}_{2}$-terminal kinase; MAP, mitogen-activated protein; MTT, 3-(4,5-dimethylthiazol-2-yl)-2,5-diphenyltetrazolium bromide; $\mathrm{NCC} \mathrm{NH}_{2}$-terminal coiled-coil; PRMT, protein arginine methyltransferase; RNAi, RNA interference; ROS, reactive oxygen species; SAM, S-adenosyl-L-methionine; siRNA, small interfering RNA; TRAF, TNF receptor-associated factor

Received 01.7.11; revised 26.9.11; accepted 17.10.11; Edited by N Chandel; published online 18.11.11
} 
of a bulky group, and it eliminates preexisting hydrogen bonds with surrounding amino-acid residues. Arginine methylation thus appears to contribute to the regulation of many physiological processes through modulation of interactions among proteins. ${ }^{21,22}$ PRMT1 was the first PRMT to be cloned and was isolated as an interacting partner of the product (BTG1/TIS1) of an immediate-early gene. ${ }^{23}$ PRMT1 is the major type I enzyme, being responsible for $>50 \%$ of asymmetric arginine methylation in cells. ${ }^{24,25}$ PRMT1mediated arginine methylation contributes to the regulation of many cellular activities including RNA processing, DNA repair, and transcription, but its precise roles remain unclear. ${ }^{19,21}$

To provide insight into the biological function of PRMT1, we have searched for new target proteins of this enzyme and now show that ASK1 is a substrate of PRMT1. The PRMT1mediated methylation of ASK1 suppressed the release of ASK1 from thioredoxin, as well as the binding between ASK1 and TRAF2, thereby inhibiting the stimulation of ASK1. Moreover, depletion of PRMT1 potentiated paclitaxel-induced ASK1 activation and apoptosis in MDA-MB-231 breast cancer cells. These findings thus suggest that PRMT1 regulates stressinduced signaling through the arginine methylation of ASK1.

\section{Results}

PRMT1 mediates arginine methylation of ASK1. Analysis of the amino acid sequence of human ASK1 revealed that eight arginine residues reside in RGG or RXR motifs, which are potential methylation sites for PRMT1. ${ }^{19,20}$ We therefore investigated whether ASK1 might be a substrate of PRMT1. To test this possibility, we first examined whether the two proteins interact physically in 293T cells transfected with expression vectors for Myc epitope-tagged ASK1 (ASK1Myc) and Flag epitope-tagged PRMT1 (Flag-PRMT1). Co-immunoprecipitation analysis showed that ASK1 indeed physically associated with PRMT1 and PRMT1(G80R), which is a methyltransferase-defective form of the enzyme with a point mutation in the SAM-binding domain (Figure 1a). The physical association of endogenous ASK1 and PRMT1 proteins was also confirmed in A549 cells by immunoblot analysis of ASK1 immunoprecipitates with antibodies to PRMT1 (Figure 1b). The extent of the interaction between ASK1 and PRMT1 was not substantially affected by treatment of the cells with $\mathrm{H}_{2} \mathrm{O}_{2}$, which stimulates ASK1 activity, or with adenosine dialdehyde (AdOx), a methylation inhibitor (Figure 1b).

We next examined whether PRMT1 was able to mediate the arginine methylation of ASK1 in an in vitro methylation assay in which GST-tagged PRMT1 was incubated with GSTtagged deletion mutants of ASK1 in the presence of $\left[{ }^{3} \mathrm{H}\right] \mathrm{SAM}$ as the methyl donor. GST-PRMT1 methylated GST-ASK1 (1-136) and histones used as a positive control. In contrast, it did not methylate GST or other GST-fused ASK1 mutants including GST-ASK1(137-656), GST-ASK1(656-1001), and GST-ASK1(1014-1374) (Figure 1c). In a separate in vitro methylation assay, ASK1-Myc was methylated by PRMT1 but not by PRMT1(G80R) (Figure 1d). In contrast, neither MKK6, SEK1, JNK1, SAPK $\beta$ (JNK3), p38, or c-Jun was methylated by PRMT1 (Supplementary Figure S1). PRMT4 (also known as Carm1) and PRMT5 did not mediate the methylation of GST-ASK1(1-136) (Figure 1e).

PRMT1 mediates the methylation of ASK1 at arginines 78 and 80 . We next examined which arginine residue (or residues) of ASK1 serves as the methylation site for PRMT1. ASK1(1-136) contains seven arginine residues, three of which ( $\mathrm{Arg}^{32}, \mathrm{Arg}^{78}$, and $\mathrm{Arg}^{80}$ ) reside in RGG or RGR sequences that serve as methylation motifs for PRMT1. ${ }^{19,20}$ We replaced these three arginine residues with lysine by sitedirected mutagenesis and examined whether the mutant proteins are methylated by PRMT1 in vitro. The replacement of $\mathrm{Arg}^{78}$ or $\mathrm{Arg}^{80}$ with lysine markedly reduced the extent of PRMT1-mediated methylation of ASK1(1-136) (Figure 2a). Moreover, replacement of both of these arginine residues with lysine abolished methylation. In contrast, replacement of $\mathrm{Arg}^{32}$ with lysine did not affect the level of PRMT1-mediated methylation of ASK1(1-136). We next examined whether PRMT1 mediates methylation of ASK1 in cultured cells. For these experiments, we generated antibodies specific for $\mathrm{Arg}^{78}$ or $\mathrm{Arg}^{80}$-methylated forms of ASK1 and confirmed their specificity (Supplementary Figure S2). We transfected 293T cells with a vector encoding Myc epitope-tagged wild-type ASK1 or ASK1(R78K/R80K) with or without a vector for FlagPRMT1. Cell lysates were then subjected to immunoprecpitation with anti-Myc antibody, and the resulting immunoprecipitates were subjected to immunoblot analysis with antibodies to $\mathrm{Arg}^{78}$-methylated ASK1. The ectopically expressed PRMT1 promoted Arg $^{78}$ methylation of ASK1, whereas it did not affect the lack of reactivity of ASK1(R78K/ $\mathrm{R} 80 \mathrm{~K}$ ) with the methylation-specific antibodies (Figure 2b). Furthermore, the PRMT1-mediated methylation of ASK1 on $\mathrm{Arg}^{78}$ was blocked by the methylation inhibitor AdOx (Figure 2c). The methyltransferase-defective mutant PRMT1(G80R) also failed to promote $\mathrm{Arg}^{78}$ methylation of ASK1 (Figure 2c). In similar experiments, the PRMT1-mediated methylation of ASK1 on $\operatorname{Arg}^{80}$ was detected by immunoblot analysis with antibodies to $\mathrm{Arg}^{80}$-methylated ASK1, and this methylation was blocked by AdOx (Supplementary Figure S3). To examine the role of endogenous PRMT1 in the arginine methylation of ASK1, we transfected MCF7 cells with small interfering RNAs (siRNAs) specific for PRMT1 or green fluorescence protein (GFP, control) mRNAs. The methylation of endogenous ASK1 on $\mathrm{Arg}^{78}$ and $\mathrm{Arg}^{80}$ apparent in MCF7 cells was inhibited by siRNA-mediated depletion of PRMT1 (Figure 2d, Supplementary Figure S3c). AdOx also suppressed the methylation of endogenous ASK1 on $\mathrm{Arg}^{78}$ and $\mathrm{Arg}^{80}$ (Figure 2e, Supplementary Figure S3d). Immunofluorescence staining with the corresponding specific antibodies detected the $\mathrm{Arg}^{78}$-methylated form of ASK1 in HeLa cells co-expressing ectopic ASK1 and PRMT1, whereas no such immunoreactivity was apparent in cells co-expressing ASK1(R78K/R80K) and PRMT1 (Figure 2f). Together, these findings suggested that PRMT1 mediates the arginine methylation of ASK1 in intact cells.

PRMT1 inhibits ASK1-JNK1 signaling induced by $\mathbf{H}_{\mathbf{2}} \mathbf{O}_{2}$. Given that PRMT1 mediates the arginine methylation of ASK1, we next examined whether PRMT1 


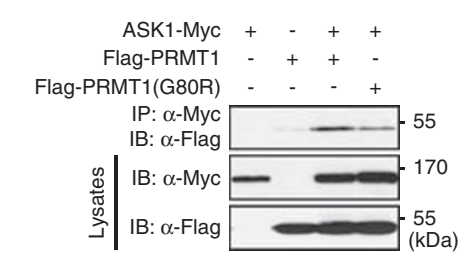

b

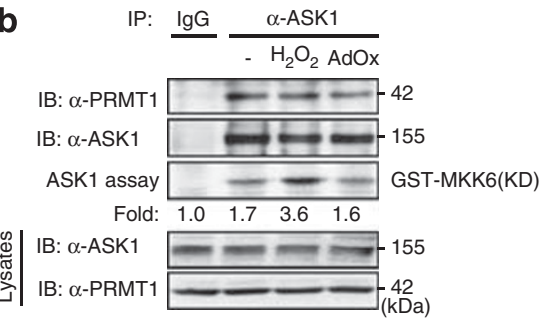

C
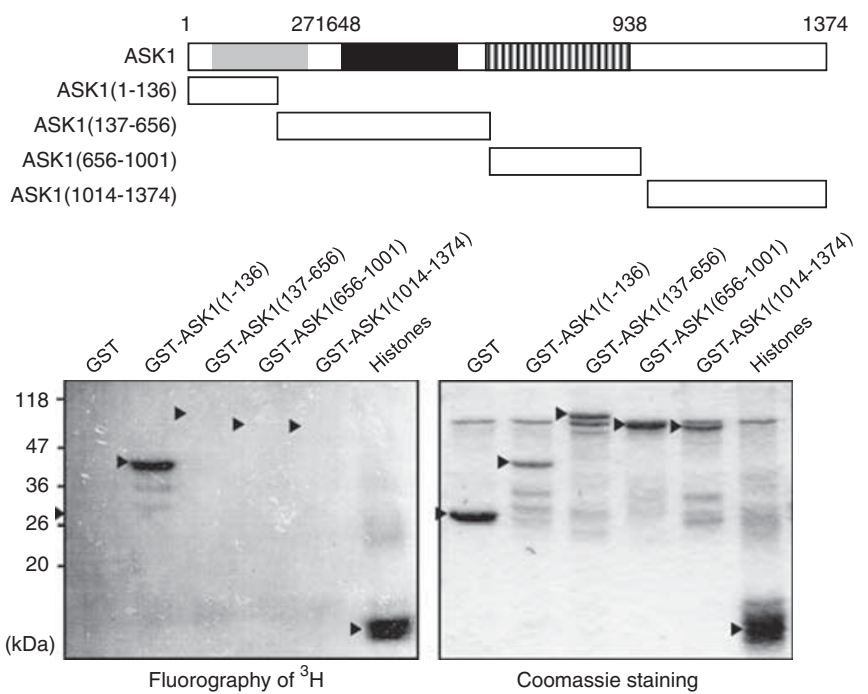

d
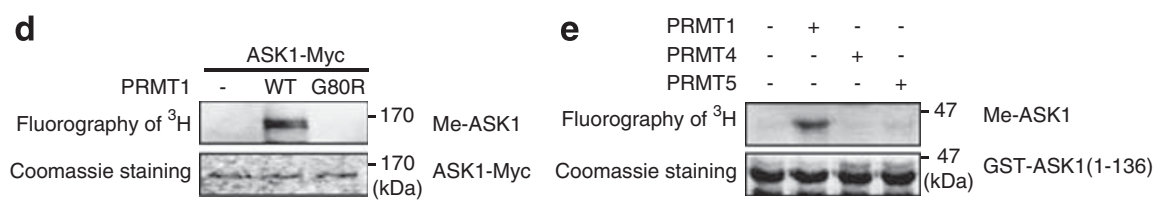

Figure 1 PRMT1 methylates ASK1 in vitro. (a) 293T cells were transfected for $48 \mathrm{~h}$ with the indicated combinations of vectors encoding ASK1-Myc, Flag-PRMT1, or Flag-PRMT1(G80R). Cell lysates were then subjected to immunoprecipitation (IP) with anti-Myc antibody, and the resulting precipitates were subjected to immunoblot analysis (IB) with anti-Flag antibody. Cell lysates were also examined directly by IB with antibodies to Myc or to Flag. (b) $\mathrm{A} 549$ cells were left untreated or treated with $\mathrm{H}_{2} \mathrm{O}_{2}(1 \mathrm{mM})$ for $30 \mathrm{~min}$ or $\mathrm{AdOx}(10 \mu \mathrm{M})$ for $12 \mathrm{~h}$. Cell lysates were then subjected to IP with control rabbit immunoglobulin $\mathrm{G}(\mathrm{IgG})$ or anti-ASK1 antibody, and the resulting precipitates were examined by immunoblot analysis with antibodies to PRMT1 or to ASK1 and for ASK1 activity by immune complex kinase assay. Cell lysates were also examined directly by immunoblot analysis with antibodies to ASK1 or to PRMT1. (c) Human ASK1 and deletion mutants thereof are shown in the upper panel; the thioredoxin-binding region (gray box), TRAF2-binding region (black box), and the kinase domain (stripped box) are indicated. Recombinant GST-PRMT1 was incubated with GST fusion proteins of the indicated ASK1 deletion mutants, GST (negative control), or a histone mixture (positive control) in the presence of $\left.{ }^{3} \mathrm{H}\right] \mathrm{SAM}$. The reaction mixtures were subjected to SDSPAGE on $12 \%$ gel, and ${ }^{3} \mathrm{H}$-labeled proteins were visualized by fluorography. The gel was also stained with Coomassie brilliant blue. The arrowheads indicate the positions of the tested proteins. (d) 293T cells transfected with an expression vector for Flag-tagged wild type (WT) or G80R mutant forms of PRMT1 were lysed and subjected to IP with anti-Flag antibody, and the resulting precipitates were assayed for in vitro methylation activity with ASK1-Myc immunoprecipitated from transfected 293T cells with anti-Myc antibody as substrate. (e) 293T cells transfected for $48 \mathrm{~h}$ with an expression vector encoding Flag-PRMT1, Flag-PRMT4, or Flag-PRMT5 were lysed and subjected to IP with anti-Flag antibody. The resulting precipitates were assayed for in vitro methylation activity with GST-ASK1(1-136) as substrate as in (c)

modulates ASK1 activity. Activation of ASK1-Myc by $\mathrm{H}_{2} \mathrm{O}_{2}$ in 293T cells was inhibited by coexpression of Flag-PRMT1 but not by that of Flag-PRMT1 (G80R) (Figure 3a). Furthermore, PRMT1 failed to inhibit the $\mathrm{H}_{2} \mathrm{O}_{2}$-induced stimulation of ASK1(R78K/R80K) (Figure $3 b$ ), suggesting that the methylation of arginines 78 and 80 underlies the inhibition of ASK1 stimulation by PRMT1. PRMT1 also inhibited ASK1induced activation of JNK1, whereas PRMT1(G80R) did not (Figure 3c). To investigate the role of endogeneous PRMT1 in ASK1 signaling, we established HeLa cells that stably expressed either GFP (control) or PRMT1 siRNAs. As expected, depletion of endogeneous PRMT1 by RNA interference (RNAi) abrogated the methylation of endogenous ASK1 on $\mathrm{Arg}^{78}$ in HeLa cells (Figure $3 \mathrm{~d}$ ). The $\mathrm{H}_{2} \mathrm{O}_{2}$-induced activation of ASK1 and JNK1 was potentiated in the cells expressing PRMT1 siRNA compared with that in those expressing GFP siRNA (Figure 3e). Such RNAi-mediated knockdown of PRMT1 also potentiated the TNF- $\alpha$-induced stimulation of ASK1 and JNK1(Supplementary Figure S4). Consistently with these results, AdOx treatment inhibited the methylation of ASK1 on $\mathrm{Arg}^{78}$ in HeLa cells (Figure $3 \mathrm{f}$ ), and it potentiated $\mathrm{H}_{2} \mathrm{O}_{2}$ induced ASK1 activition in the same cells (Figure $3 \mathrm{~g}$ ). Together, these results suggested that PRMT1 inhibits the stimulation of ASK1-JNK signaling by catalyzing arginine methyltion of ASK1. 
a GST-ASK1 (1-136)

GST-ASK1 (1-136: R32K) GST-ASK1 (1-136: R78K)

GST-ASK1 (1-136: R80K)

GST-ASK1 (1-136: R78K/R80K)

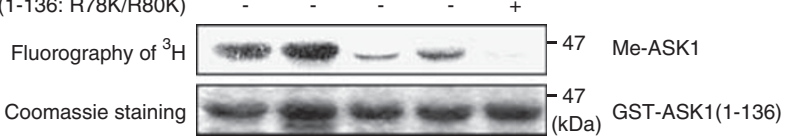

b

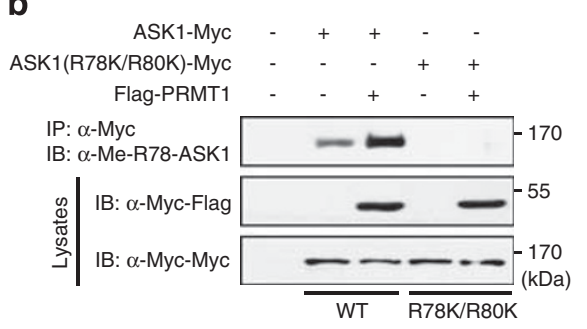

d

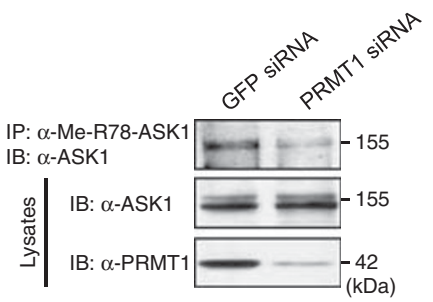

C

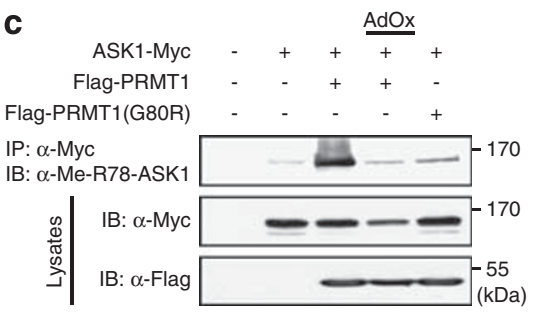

e

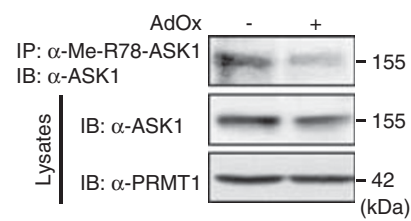

f
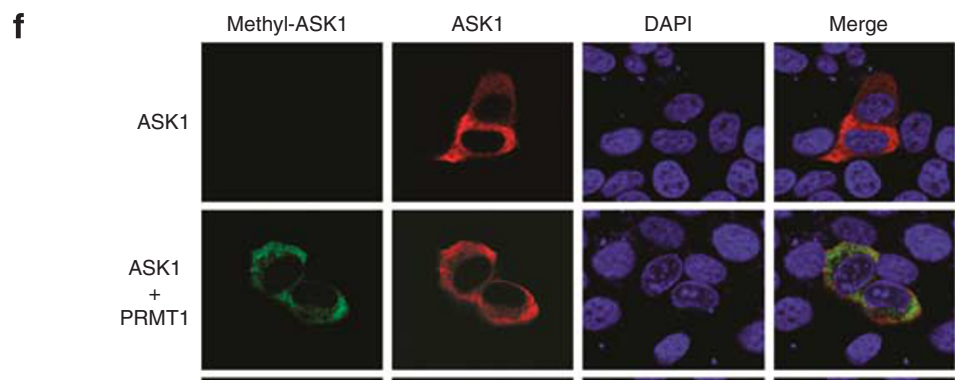

ASK1(R78K/R80K)

$\stackrel{+}{+}$
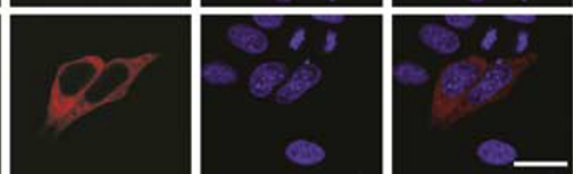

Figure 2 PRMT1 mediates arginine methylation of ASK1 in intact cells. (a) In vitro methylation of GST-ASK1(1-136) or its Arg-to-Lys mutants was examined in the presence of GST-PRMT1 and $\left.{ }^{3} \mathrm{H}\right] \mathrm{SAM}$. Reaction mixtures were subjected to SDS-PAGE, and ${ }^{3} \mathrm{H}$-labeled proteins were visualized by fluorography. The gel was also stained with Coomassie brilliant blue. (b) 293T cells were transfected for $48 \mathrm{~h}$ with expression vectors encoding ASK1-Myc, ASK1(R78K/R80K)-Myc, and Flag-PRMT1, as indicated. Cell lysates were then subjected to immunoprecipitation with anti-Myc antibody, and the resulting precipitates were examined by immunoblot with antibody to Arg ${ }^{78}$-methylated ASK1 ( $\alpha$-Me-R78-ASK1). Cell lysates were also examined directly by immunoblot analysis with antibodies to Myc or to Flag. (c) $293 \mathrm{~T}$ cells were transfected for $48 \mathrm{~h}$ with expression vectors encoding ASK1-Myc, Flag-PRMT1, and Flag-PRMT1(G80R), as indicated. The cells were then incubated with AdOx (10 $\mu$ M) or dimethyl sulfoxide (DMSO, $0.1 \%$ ) vehicle for $12 \mathrm{~h}$, lysed, and subjected to immunoprecipitation with anti-Myc antibody. The resulting precipitates and cell lysates were subjected to immunoblot analysis with the indicated antibodies. (d and e) MCF7 cells were transfected for $48 \mathrm{~h}$ with control (GFP) or PRMT1 siRNAs (d) or were treated for $12 \mathrm{~h}$ with AdOx (10 $\mu \mathrm{M}$ ) or DMSO $(0.1 \%)(e)$. Cell lysates were then subjected to immunoprecipitation with antibody to $\mathrm{Arg}^{78}$-methylated ASK1, and the resulting precipitates were subjected to immunoblot analysis with anti-ASK1 antibody. Cell lysates were also examined directly by immunoblot analysis with antibodies to ASK1 or to PRMT1. (f) HeLa cells were transfected for $48 \mathrm{~h}$ with an expression vector encoding ASK1-Myc or ASK1(R78K/R80K)-Myc without or with a vector for Flag-PRMT1. The cells were then fixed and immunostained with antibodies to Myc and to $\mathrm{Arg}^{78}$-methylated ASK1. Nuclei were visualized by staining with $4^{\prime}, 6^{\prime}$-diamidino-2-phenylindole dihydrochloride (DAPI). Scale bar, $20 \mu \mathrm{m}$

PRMT1-mediated methylation of ASK1 promotes the association between ASK1 and thioredoxin. The formation of a complex between ASK1 and thioredoxin is thought to maintain the kinase activity of ASK1 in the basal state. ${ }^{15}$ The production of ROS associated with oxidative stress or with exposure of cells to certain stimuli results in the oxidation of thioredoxin and its consequent dissociation from
ASK1. ASK1 released from oxidized thioredoxin then becomes activated by association with TRAF proteins such as TRAF2 and TRAF6 and subsequent phosphorylation of the kinase activation loop. ${ }^{16,18}$ The homo-oligomerization of ASK1 through its coiled-coil domains in the $\mathrm{NH}_{2}$ - and $\mathrm{COOH}-$ terminal regions is also an integral part of the mechanism of ASK1 activation. ${ }^{17,18}$ In unstimulated states, inactive ASK1 

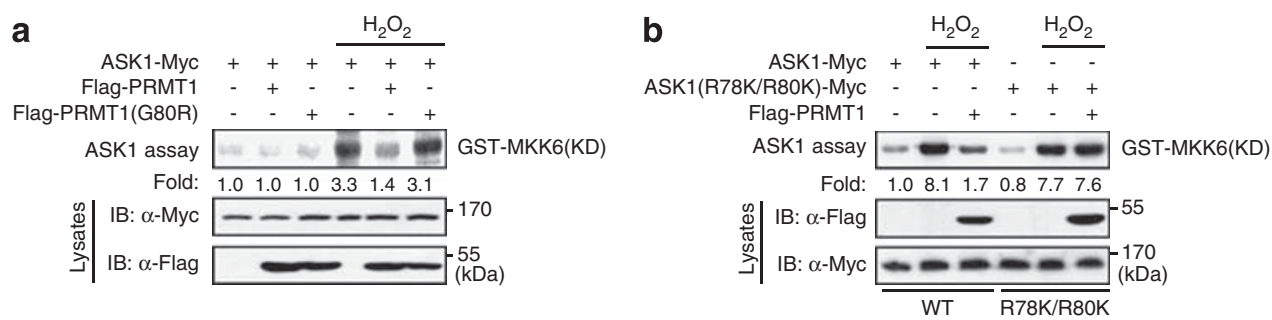

C

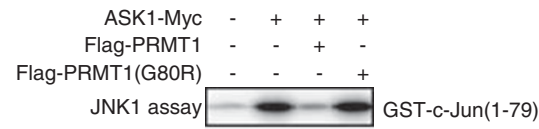

e

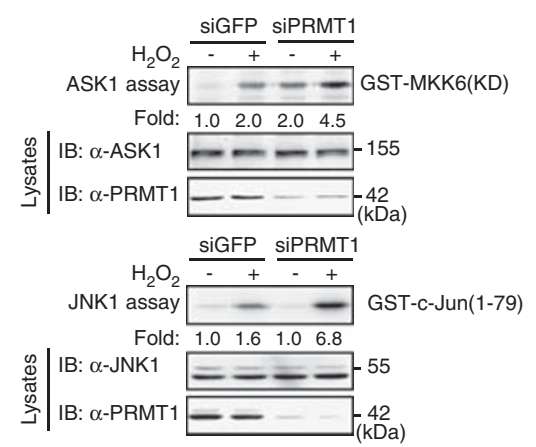

f

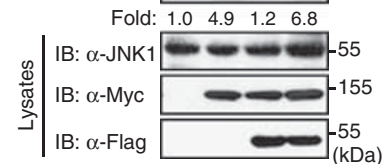

d

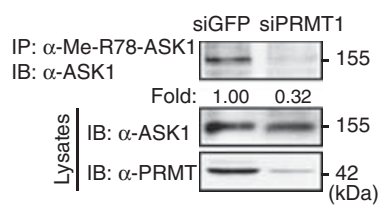

g

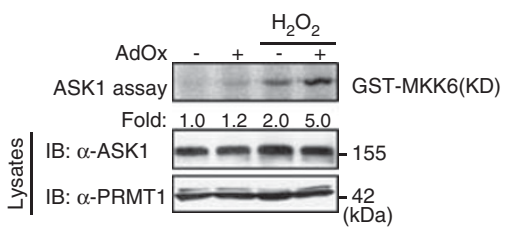

Figure 3 PRMT1 inhibits $\mathrm{H}_{2} \mathrm{O}_{2}$-induced activation of ASK1 and JNK1 in intact cells. (a and $\left.\mathbf{b}\right)$ 293T cells were transfected for $48 \mathrm{~h}$ with the indicated combinations of plasmid vectors for ASK1-Myc, ASK1(R78K/R80K)-Myc, Flag-PRMT1, and Flag-PRMT1(G80R). The cells were then left untreated or treated with $1 \mathrm{mM} \mathrm{H}_{2} \mathrm{O}_{2}$ for $30 \mathrm{~min}$, lysed, and subjected to immunoprecipitation with anti-Myc antibody. The resulting precipitates were examined for ASK1 activity by immune complex kinase assay with GST-MKK6(K82A) as substrate. The relative activities are shown below each lane. Cell lysates were also examined directly by immunoblot analysis with antibodies to Myc or to Flag. (c) 293T cells were transfected for $48 \mathrm{~h}$ with an expression vector encoding ASK1-Myc alone or together with a vector for Flag-PRMT1 or Flag-PRMT1(G80R). Cell lysates were then subjected to immunoprecipitation with anti-JNK1 antibody, and the resulting precipitates were examined for JNK1 activity by immune complex kinase assay with GST-c-Jun(1-79) as substrate. (d) HeLa cells stably expressing either GFP or PRMT1 siRNAs were lysed and then subjected to immunoprecipitation with antibody to $\mathrm{Arg}^{78}$-methylated ASK1. The resulting precipitates were subjected to immunoblot analysis with anti-ASK1 antibody. Cell lysates were also examined directly by immunoblot analysis with antibodies to ASK1 or to PRMT1. (e) HeLa cells stably expressing either GFP or PRMT1 siRNAs were left untreated or treated with $1 \mathrm{mM} \mathrm{H}_{2} \mathrm{O}_{2}$ for 30 min, lysed, and subjected to immunoprecipitation with antibodies to ASK1 (upper panel) or to JNK1 (lower panel). The resulting precipitates were assayed for ASK1 (upper panel) or JNK1 (lower panel) activity by immune complex kinase assay. (f) HeLa cells were treated for $12 \mathrm{~h}$ with $10 \mu \mathrm{M}$ AdOx or $0.1 \%$ DMSO. Cell lysates were examined for the methylation of ASK1 with antibodies to $\mathrm{Arg}^{78}$-methylated ASK1 and to ASK1 as in (d). (g) HeLa cells were left untreated or treated with $10 \mu \mathrm{M}$ AdOx for $12 \mathrm{~h}$, and then incubated further in the absence or presence of $1 \mathrm{mM} \mathrm{H}_{2} \mathrm{O}_{2}$ for $30 \mathrm{~min}$. Cell lysates were examined for ASK1 activity by immune complex kinase assay as in (e)

forms a homo-oligomer through the homophilic interaction of the CCC domains. Upon ROS-induced release of thioredoxin from ASK1 and subsequent recruitment of TRAF2 or TRAF6 to ASK1, the NCC domains of ASK1 becomes tightly associated through the homophilic interaction, thereby facilitating the formation of active ASK1 complex. ${ }^{2,18}$

To characterize further the molecular mechanism by which PRMT1 inhibits ASK1 activation, we first examined the possible effect of PRMT1 on the homo-oligomerization of ASK1 in 293T cells transfected with plasmid vectors for ASK1-Flag and ASK-Myc without or with a vector for FlagPRMT1. Co-immunoprecipitation analysis revealed that PRMT1 did not affect the homo-oligomerization of ASK1 regardless of the presence of $\mathrm{H}_{2} \mathrm{O}_{2}$ (Figure 4a). Next, we examined the effect of PRMT1 on ASK1 homo-oligomerization through the hemophilic interaction of the NCC, which appears to be essential for ROS-induced ASK1 activation, ${ }^{18}$ after transfecting 293T cells with vectors encoding Flag-PRMT1,
Flag-ASK1(1-656), and HA-ASK1(1-656). ASK1(1-656) deletion mutant includes the NCC domain but not CCC domain. $\mathrm{H}_{2} \mathrm{O}_{2}$ treatment increased the interaction between HA-ASK1(1-656) and Flag-ASK1(1-656) in co-immunoprecipitation analysis, and this $\mathrm{H}_{2} \mathrm{O}_{2}$-induced homophilic interaction was inhibitd by PRMT1 (Figure $4 b$ ). These results thus suggested that PRMT1 negatively regulates the homooligomerization of ASK1 through the homophilic interaction of its NCC domain. Given that dissociation of thioredoxin from ASK1 and association of TRAF2 or TRAF6 with ASK1 promote the hemophilic interaction of the NCC domain of ASK $1,{ }^{18}$ in the following experiments we investigated the effect of PRMT1 on the binding of ASK1 to thioredoxn or to TRAF2. We examined the effect of PRMT1 on the interaction between ASK1 and thioredoxin in 293T cells transfected with vectors encoding ASK1-Myc and hemagglutinin epitope (HA)-tagged thioredoxin 1 in the absence or presence of a vector for Flag-PRMT1 or Flag-PRMT1(G80R). ASK1 


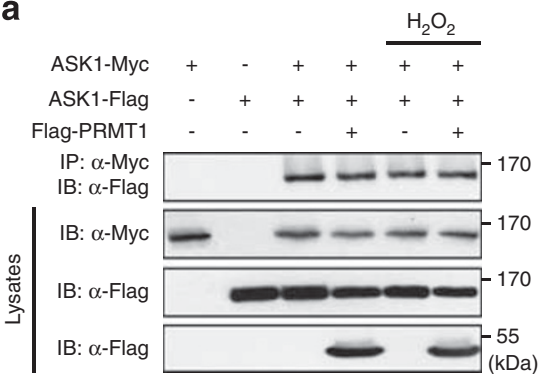

b

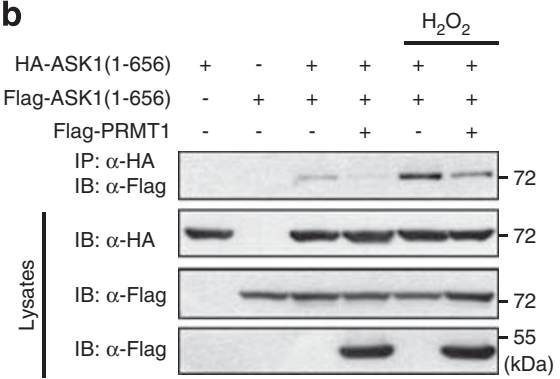

Figure 4 Effect of PRMT1 on the homo-oligomerization of ASK1. The 293T cells were transfected for $48 \mathrm{~h}$ with indicated combination of expression vectors for ASK1-Myc, ASK1-Flag, HA-ASK1(1-656), Flag-ASK1(1-656), and Flag-PRMT1. The cells were then left untreated or treated with $1 \mathrm{mM} \mathrm{H}_{2} \mathrm{O}_{2}$ for 15 min, lysed, and subjected to immunoprecipitation with antibodies to Myc epitope (a) or to HA epitope (b). The resulting precipitates were subjected to immunoblot analysis with anti-Flag antibody. Cell lysates were also examined directly by immunoblot analysis with indicated antibodies

a

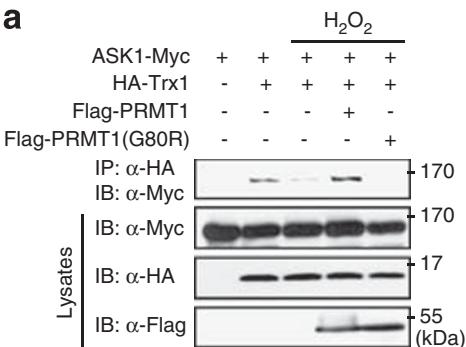

b

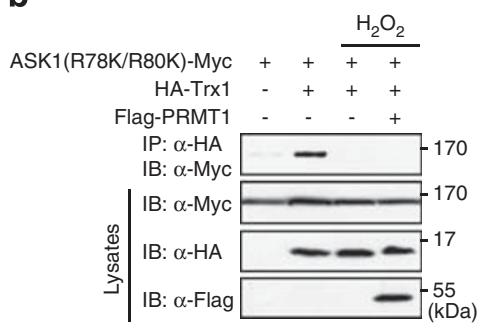

e

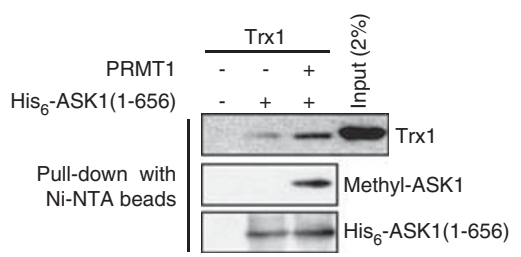

Figure 5 PRMT1-mediated methylation of ASK1 promotes the interaction between ASK1 and thioredoxin. (a and $\mathbf{b}) 293 \mathrm{~T}$ cells were transfected for $48 \mathrm{~h}$ with expression vectors encoding ASK1-Myc, ASK1(R78K/R80K)-Myc, HA-thioredoxin-1 (HA-Trx1), Flag-PRMT1, and Flag-PRMT1(G80R), as indicated. The cells were then left untreated or treated with $1 \mathrm{mM} \mathrm{H}_{2} \mathrm{O}_{2}$ for $15 \mathrm{~min}$, lysed, and subjected to immunoprecipitation with anti-HA antibody. The resulting precipitates were subjected to immunoblot analysis with anti-Myc antibody. Cell lysates were also examined directly by immunoblot analysis with antibodies to Myc, to HA, or to Flag. (c) HeLa cells stably expressing GFP or PRMT1 siRNAs were left untreated or treated with $1 \mathrm{mM} \mathrm{H}_{2} \mathrm{O}_{2}$ for $15 \mathrm{~min}$. Cell lysates were subjected to immunoprecipitation with anti-ASK1 antibody, and the resulting precipitates were examined by immunoblot analysis with antibody to thioredoxin 1. (d) Two biotinylated 13-residue peptides corresponding to amino acids 74 to 86 (SSATR ${ }^{78} \mathrm{GR}^{80} \mathrm{GSSVGG)}$ of ASK1, one unmodified and the other asymmetrically dimethylated at $\mathrm{Arg}^{78}$ and $\mathrm{Arg}^{80}$, were individually applied to streptavidin-agarose beads, which were then incubated overnight at $4^{\circ} \mathrm{C}$ with thioredoxin 1 . The bead-bound material and a portion (4\%) of the thioredoxin-1 input to the binding reaction were then subjected to immunoblot analysis with antibody to thioredoxin 1. (e) His 6 -ASK1(1-656) that had or had not been methylated in vitro by Flag-PRMT1 was incubated overnight at $4^{\circ} \mathrm{C}$ with the reduced form of thioredoxin 1 and was then precipitated with Ni-NTA beads. The bead-bound material and a portion (2\%) of the thioredoxin 1 input to the binding reaction were then subjected to immunoblot analysis with antibodies to thioredoxin 1 , to $\mathrm{Arg}^{78}$-methylated ASK1, or to ASK1

physically associated with thioredoxin, and this association was inhibited by $\mathrm{H}_{2} \mathrm{O}_{2}$ treatment (Figure 5a). However, the interaction between ASK1 and thioredoxin was not disrupted by $\mathrm{H}_{2} \mathrm{O}_{2}$ in the cells expressing PRMT1, whereas it was disrupted in those expressing PRMT1(G80R). In contrast, PRMT1 did not affect the inhibitory action of $\mathrm{H}_{2} \mathrm{O}_{2}$ on the interaction between $A S K 1$ (R78K/R80K) and thioredoxin (Figure $5 \mathrm{~b}$ ). These results thus showed that ectopically expressed PRMT1, by methylating ASK1, prevents the $\mathrm{H}_{2} \mathrm{O}_{2}$-induced release of ASK1 from thioredoxin. Furthermore, siRNA-mediated depletion of endogenous PRMT1 in HeLa cells prevented the association between ASK1 and thioredoxin even in the absence of $\mathrm{H}_{2} \mathrm{O}_{2}$ (Figure 5c), suggesting that PRMT1-mediated ASK1 methylation promotes the interaction between ASK1 and thioredoxin. Consistent with this notion, a peptide 'pull-down assay' performed with unmodified or dimethylated 13-amino acid peptides (SSATR ${ }^{\mathbf{7 8}} \mathrm{GR}^{\mathbf{8 0}} \mathrm{GSSVGG)}$ corresponding to amino acids $74-86$ of ASK1 revealed that thioredoxin bound to the peptide dimethylated at $\mathrm{Arg}^{78}$ and $\mathrm{Arg}^{80}$ more efficiently than it did to the unmodified peptide (Figure $5 d$ ). The extent of the binding between thioredoxin and $\mathrm{His}_{6}$-tagged ASK1(1-656) in vitro was also increased as a result of prior methylation of $\mathrm{His}_{6}$-ASK1(1-656) by PRMT1 (Figure 5e).

We next examined whether PRMT1-mediated arginine methylation affects the interaction between ASK1 and TRAF2. Co-immunoprecipitation analysis with transfected 
293T cells revealed that the interaction between ASK1-Myc and Flag-TRAF2 was inhibited in cells co-expressing PRMT1 but not in those co-expressing PRMT1(G80R) (Figure 6a). In contrast, the interaction between ASK1(R78K/R80K) and TRAF2 was not inhibited by coexpression of PRMT1 (Figure 6b). Moreover, RNAi-mediated knockdown of PRMT1 potentiated the binding between endogenous ASK1 and TRAF2 in HeLa cells (Figure 6c). However, in vitro binding analysis revealed that the direct interaction of $\mathrm{His}_{6}$-ASK1 (1-656) with GST-TRAF2 was not affected by prior PRMT1mediated methylation of $\mathrm{His}_{6}-\mathrm{ASK} 1(1-656)$ (Figure 6d). Given that dissociation of ASK1 from thioredoxin renders ASK1 available for binding to TRAF2, ${ }^{26}$ our data thus suggested that PRMT1-mediated methylation of ASK1 negatively regulates the interaction between ASK1 and TRAF2 in intact cells by promoting the association between ASK1 and thioredoxin and thereby reducing the availability of free ASK1.

PRMT1 suppresses paclitaxel-induced stimulation of ASK1 and cell death in breast cancer cells. The ASK1JNK signaling pathway mediates the induction of apoptosis by microtubule-interfering agents such as paclitaxel. ${ }^{27}$ Depletion of ASK1 by RNAi thus inhibited paclitaxelinduced apoptosis in MDA-MB-231 human breast cancer cells (Figure 7a). Given that PRMT1 methylates and thereby inhibits the activation of ASK1, we next examined whether PRMT1 negatively regulates paclitaxel-induced apoptosis in breast cancer cells. Three breast cancer cell lines, MDAMB-231, MCF7, and T47D, were studied. The abundance of PRMT1 was relatively high in MDA-MB-231 and MCF7 cells but was much lower in T47D cells (Supplementary Figure S5).
Notably, RNAi-mediated depletion of PRMT1 inhibited the methylation of ASK1 in MDA-MB-231 (Supplementary Figure S6a) and MCF7 cells (Figure 2d, Supplementary Figure S3c).

Paclitaxel induced apoptosis in MDA-MB-231 (Figure 7b) and MCF7 cells (Supplementary Figure S7), and the RNAimediated depletion of PRMT1 potentiated this effect in both cell lines (Figure 7b, Supplementary Figure S7). In addition, clonal growth assay (Figure 7c) and cell viability assay (Figure 7d) showed that RNAi-mediated silencing of PRMT1 augmented sensitivity to paclitaxel in MDA-MB-231 cells. Furthermore, the potentiating effect of RNAi-mediated PRMT1 depletion on apoptosis (Figure 7b) or cytotoxicity (Figure 7d) was abrogated by an additional depletion of ASK1 by RNAi. Conversely, forced expression of PRMT1, which increased the methylation of ASK1 on $\mathrm{Arg}^{78}$ (Supplementary Figure S6b), inhibited paclitaxel-induced apoptosis in T47D cells (Figure 7e). Moreover, ectopic PRMT1 inhibited paclitaxel-induced apoptosis in T47D cells co-expressing ectopic ASK1 but not in those coexpressing ASK1(R78K/R80K) (Figure 7f), suggesting that arginine methylation of ASK1 is responsible for the inhibitory effect of PRMT1 on paclitaxelinduced apoptotic cell death.

We next examined the effect of RNAi-mediated PRMT1 depletion on paclitaxel-induced ASK1 and JNK1 activation in MDA-MB-231 cells. Paclitaxel induced the dissociation of ASK1 from thioredoxin and the association between ASK1 and TRAF2 (Figure 7h), as well as ASK1 and JNK1 activation (Figure 7g) in cells expressing GFP siRNA, and these effects of paclitaxel were potentiated in cells expressing PRMT1 siRNA. Collectively, these results suggested that PRMT1, by methylating ASK1, negatively regulates the paclitaxel-
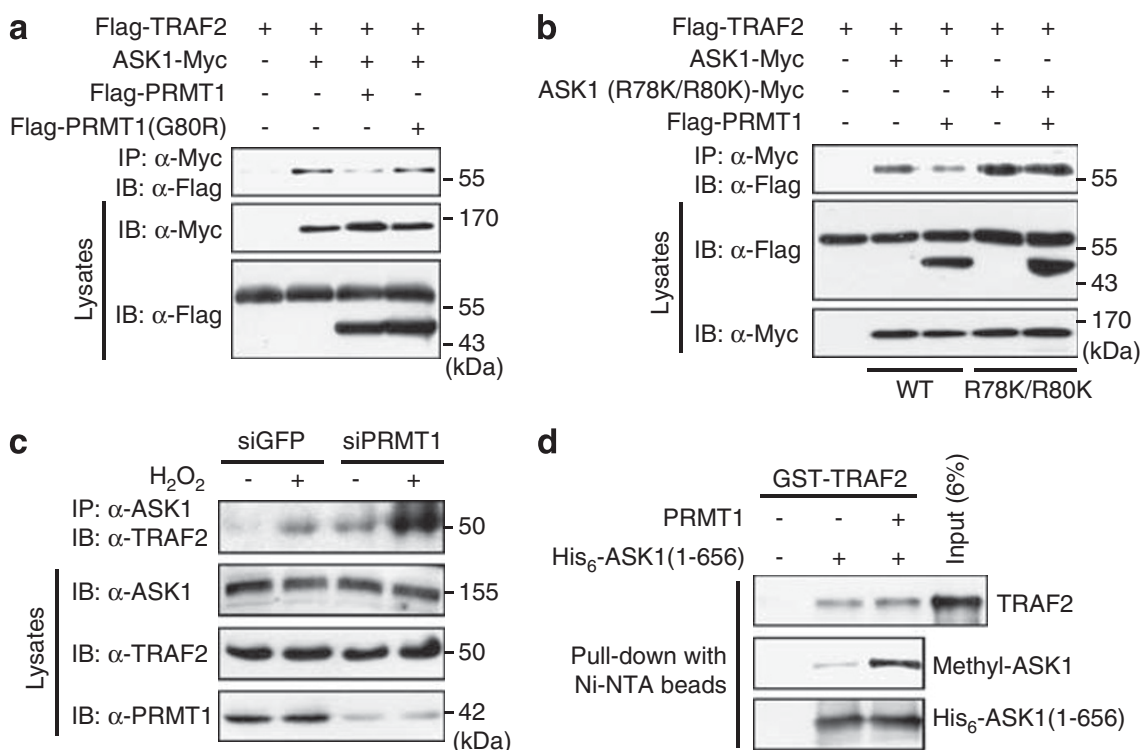

Figure 6 PRMT1-mediated methylation of ASK1 inhibits the interaction between ASK1 and TRAF2. (a and $\mathbf{b}) 293 \mathrm{~T}$ cells transfected for $48 \mathrm{~h}$ with expression vectors encoding ASK1-Myc, ASK1(R78K/R80K)-Myc, Flag-TRAF2, Flag-PRMT1, and Flag-PRMT1(G80R), as indicated, were lysed and subjected to immunoprecipitation with anti-Myc antibody. The resulting precipitates were subjected to immunoblot analysis with anti-Flag antibody. Cell lysates were also examined directly by immunoblot with antibodies to Myc or to Flag. (c) HeLa cells stably expressing GFP or PRMT1 siRNAs were left untreated or treated with $1 \mathrm{mM} \mathrm{H}_{2} \mathrm{O}_{2}$ for 15 min, lysed, and subjected to immunoprecipitation with anti-ASK1 antibody. The resulting precipitates were subjected to immunoblot analysis with anti-TRAF2 antibody. (d) $\mathrm{His}_{6}{ }^{-}$- SK1 (1-656) that had or had not been methylated in vitro by Flag-PRMT1 was incubated overnight at $4^{\circ} \mathrm{C}$ with GST-TRAF2 and then precipitated with Ni-NTA beads. The bead-bound material and a portion (6\%) of the GST-TRAF2 input to the binding reaction were subjected to immunoblot analysis with antibodies to TRAF2, to Arg ${ }^{78}$-methylated ASK1, or to ASK1 
induced stimulation of ASK1 and apoptotic cell death in breast cancer cells.

\section{Discussion}

We have shown that PRMT1 catalyzes the methylation of ASK1 on arginines 78 and 80 and that such PRMT1-mediated methylation negatively regulates the stress-induced stimulation of ASK1 and downstream signaling events that lead to apoptotic cell death.
ASK1 is activated during the cellular response to ROS and other stressors through a multistep process that includes ASK1 homo-dimerization, dissociation of ASK1 from thioredoxin, and its association with TRAF2 or TRAF6. ${ }^{1,2}$ PRMTmediated methylation does not alter the positive charge of an arginine residue, but it does increase steric hindrance as a result of the addition of the bulky methyl group (or groups) and removes a potential hydrogen bond donor on the guanidino group, thereby potentially affecting protein-protein interactions. $^{21,22}$ We thus found that PRMT1-mediated methylation

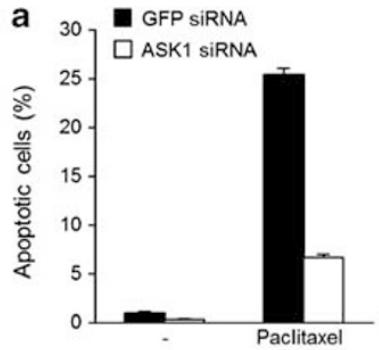

C

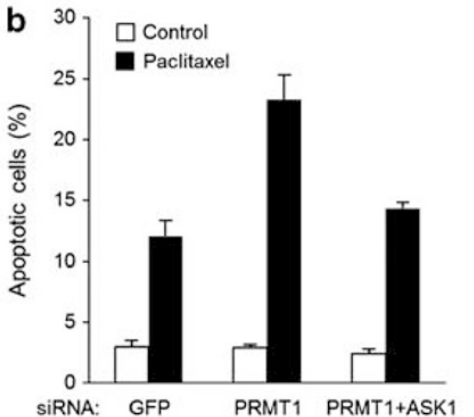

d
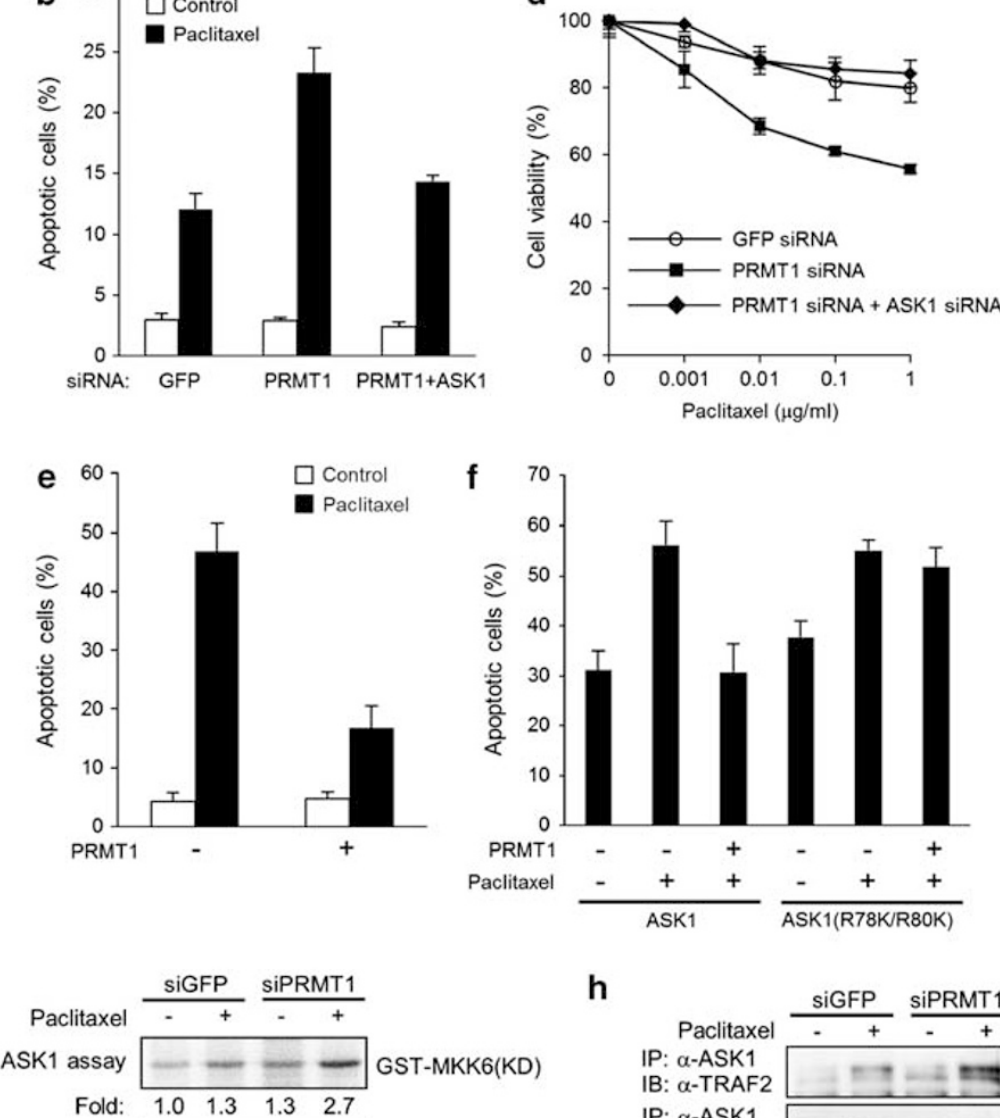

JNK1 assay $-\ldots$ GST-C-Jun(1-79)

Fold: $\quad \begin{array}{llll}1.0 & 1.6 & 1.7 & 5.4\end{array}$
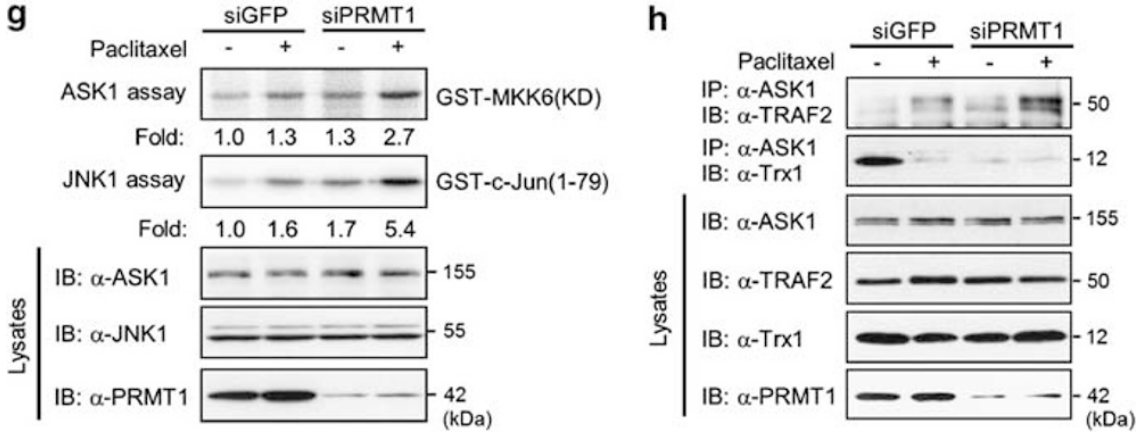
of ASK1 potentiated the interaction between ASK1 and thioredoxin. Indeed, our results show that arginine methylation of ASK1 promoted the binding of ASK1 to thioredoxin even in the presence of ROS and consequently blocked the recruitment of TRAF2 to ASK1. We also observed that PRMT1-mediated methylation of ASK1 suppressed the homophilic interaction of the $\mathrm{NH}_{2}$-terminal coiled-coil domain of ASK1, which is a critical step for ASK1 activation. ${ }^{18}$ With these findings, we propose a schematic model for the PRMT1mediated regulation of ASK1 activity (Figure 8).

PRMT1 was recently shown to methylate the transcription factor FOXO1 at an arginine residue within a consensus phosphorylation motif for Akt, resulting in inhibition of
Akt-mediated phosphorylation of $\mathrm{FOXO1.}^{28}$ Interestingly, the PRMT1-mediated methylation sites of ASK1, arginines 78 and 80 residues, are located in close proximity to Ser ${ }^{83}$, a phosphorylation site for Akt. Both Akt1 and Akt2 phosphorylate ASK1 and thereby inhibit its activity. ${ }^{6,7}$ In contrast to FOXO1, however, PRMT1-mediated arginine methylation had no substantial effect on Akt-mediated phosphorylation of ASK1 on $\mathrm{Ser}^{83}$ (Supplementary Figure S8).

PRMT1 mediates arginine methylation of histones, transcription factors, and several RNA binding proteins related to transcription, suggesting that it contributes to the regulation of gene expression. ${ }^{19}$ However, PRMT1 has also been found to methylate key components of important signaling pathways
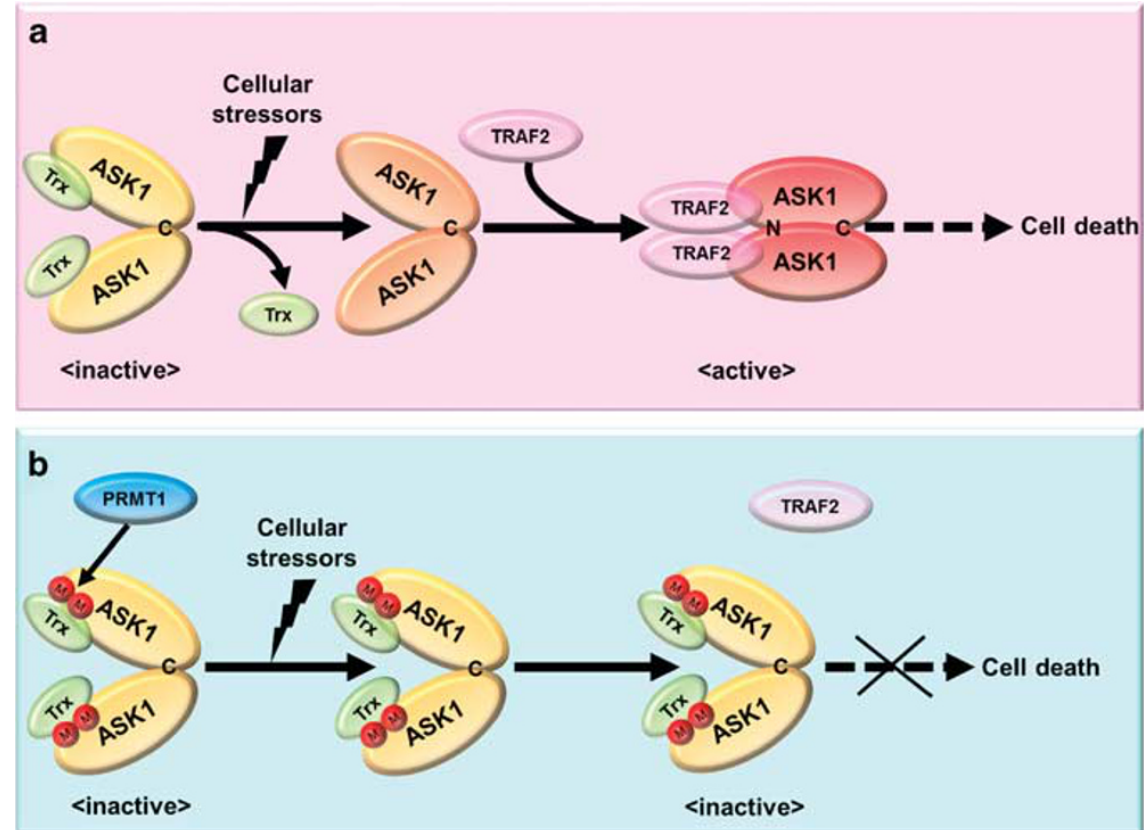

Figure 8 A proposed model for the regulation of ASK1 by PRMT1-mediated arginine methylation. (a) In an inactive state, ASK1 associates with the reduced form of thioredoxin ( $\mathrm{Trx}$ ) through its $\mathrm{NH}_{2}$-terminal region and forms a homo-oligomer through the $\mathrm{COOH}$-terminal coiled-coil domain (denoted as ' $\mathrm{C}$ '). Exposure of cells to various cellular stressors including ROS induces the dissociation of thioredoxin from ASK and the recruitment of TRAF2 (or TRAF6) to ASK1. TRAF2 (or TRAF6) promotes the homophilic interaction of the $\mathrm{NH}_{2}$-terminal coiled-coil domain (denoted as ' $\mathrm{N}$ ') of ASK1, facilitating the formation of active ASK1 complex. Persistent activation of the ASK1 signaling leads to induction of cell death. (b) PRMT1, when its expression or activity is elevated in cells, mediates arginine methylation of ASK1. Arginine methylation of ASK1 abrogates the release of thioredoxin from ASK1 and the subsequent association between ASK1 and TRAF2, thereby inhibiting the homophilic interaction of the $\mathrm{NH}_{2}$-terminal coiled-coil domain of ASK1. Therefore, PRMT1-mediated methylation of ASK1 suppresses the activation of ASK1 and its downstream signaling processes, leading to aberrant defects of cell death

Figure 7 PRMT1 suppresses paclitaxel-induced ASK1 activation and apoptosis in breast cancer cells. (a and $\mathbf{b})$ MDA-MB-231 cells transfected for $48 \mathrm{~h}$ with GFP siRNA (control) or ASK1 siRNA (a) or PRMT1 siRNA either alone or together with ASK1 siRNA (b) were incubated for $48 \mathrm{~h}$ with paclitaxel $(1 \mu \mathrm{g} / \mathrm{ml})$ or DMSO $(0.1 \%)$, fixed, and stained with propidium iodide (PI). The cells were then subjected to flow cytometry for determination of the percentage of apoptotic (sub-G1 phase) cells. Data are means \pm S.D. from three independent experiments. (c) MDA-MB-231 cells stably expressing GFP or PRMT1 siRNA were incubated for $2 \mathrm{~h}$ with $0.1 \%$ DMSO or indicated concentrations of paclitaxel. The cells were then washed, incubated further in fresh medium for 14 days, fixed with $3.7 \%$ paraformaldehyde, and stained with $0.5 \%$ crystal violet. (d) MDA-MB-231 cells were transfected for $48 \mathrm{~h}$ with siRNAs for GFP, PRMT1, or PRMT1 plus ASK1. The cells then were incubated for an additional $48 \mathrm{~h}$ with $0.1 \%$ DMSO or indicated concentrations of paclitaxel. Cell viability was determined by MTT assay, as described in Materials and Methods. The results are presented as means \pm S.D. from three independent experiments. (e and f) T47D cells were transfected for $48 \mathrm{~h}$ with a vector for GFP alone or together with a vector for Flag-PRMT1 (e), or with a vector for GFP without or with vectors for ASK1-Myc, ASK1(R78K/R80K)-Myc, and Flag-PRMT1 as indicated (f). The cells were then treated for $48 \mathrm{~h}$ with paclitaxel $(1 \mu \mathrm{g} / \mathrm{ml})$ or DMSO $(0.1 \%)$, fixed, and stained with DAPI. DAPI-stained nuclei in GFP-positive cells were examined for apoptotic morphology by fluorescence microscopy. The percentages of GFP-expressing cells positive for apoptosis are presented as means \pm S.D. from three independent experiments. (g) MDA-MB-231 cells transfected for $48 \mathrm{~h}$ with GFP or PRMT1 siRNAs were treated for $2 \mathrm{~h}$ with paclitaxel $(1 \mu \mathrm{g} / \mathrm{ml})$ or DMSO $(0.1 \%)$, lysed, and subjected to immunoprecipitation with antibodies to ASK1 or to JNK1. The resulting precipitates were subjected to immune complex kinase assays of ASK1 or JNK1 activity, respectively. The cell lysates were also examined directly by immunoblot with the indicated antibodies. (h) MDA-MB-231 cells transfected for $48 \mathrm{~h}$ with GFP or PRMT1 siRNAs were incubated for $90 \mathrm{~min}$ with paclitaxel $(1 \mu \mathrm{g} / \mathrm{ml}$ ) or DMSO $(0.1 \%)$, lysed, and subjected to immunoprecipitation with anti-ASK1 antibody. The resulting precipitates were subjected to immunoblot analysis with antibodies to TRAF2 or to thioredoxin 1. Cell lysates were also examined directly by immunoblot with the indicated antibodies 
such as estrogen receptor- $\alpha$. The methylation of estrogen receptor- $\alpha$ in the cellular response to estrogen facilitates the assembly of a complex that comprises the receptor, the tyrosine kinase Src, and the p85 subunit of phosphoinositide 3-kinase and that contributes to the nongenomic actions of estrogen. ${ }^{29}$ Our present findings extend the biological role of protein arginine methylation by suggesting that, similar to protein phosphorylation, it is a posttranslational modification that regulates the function of a protein kinase during intracellular signaling processes.

Expression of specific isoforms of PRMT1 is increased in breast cancer and colon cancer cells compared with that in the corresponding normal cells. ${ }^{30,31}$ PRMT1 has also been shown to function as a component of the oncogenic transcriptional complex in mixed-lineage leukemia. ${ }^{32}$ PRMT1 and protein methylation have thus been implicated in oncogenesis, ${ }^{22,33,34}$ although the precise role of PRMT1 in the emergence and progression of cancer remains obscure. In this regard, we have now found that PRMT1 attenuated paclitaxel-induced apoptosis in breast cancer cells through regulation of the ASK1-JNK pathway, which mediates the induction of apoptosis in cancer cells by chemotherapeutic agents. ${ }^{27,35}$ Although depletion of PRMT1 potentiated paclitaxel-induced ASK1 activation and apoptotic cell death, overexpression of PRMT1 had the opposite effects. PRMT1-mediated methylation of ASK1 might therefore contribute to drug resistance in cancer cells, and development of PRMT1-specific inhibitors may represent a potential strategy to improve the efficiency of chemotherapy in cancer patients.

\section{Materials and Methods \\ Cell culture and transfection. Human embryonic kidney 293T cells, human cervical cancer HeLa cells, human lung adenocarcinoma A549 cells, and human breast cancer T47D, MCF7, and MDA-MB-231 cells were maintained under an atmosphere of $5 \% \mathrm{CO}_{2}$ at $37^{\circ} \mathrm{C}$ in Dulbecco's modified Eagle's medium (Hyclone, South Logan, UT, USA) supplemented with $10 \%$ fetal bovine serum (Hyclone). Cells were transfected with expression vectors for the indicated proteins by the calcium phosphate method or with the use of Lipofectamine (Invitrogen, Carlsbad, CA, USA).}

Antibodies. Rabbit polyclonal antibodies to ASK1, to TRAF2, and to JNK1 were purchased from Santa Cruz Biotechnology (Santa Cruz, CA, USA). Mouse monoclonal antibodies to ASK1 and to PRMT1 were obtained from Abcam (Cambridge, MA, USA), those to thioredoxin 1 from Ab Frontier (Seoul, Korea), those to Flag from Sigma (St. Louis, MO, USA), those to HA from Roche (Nutley, $\mathrm{NJ}$, USA), and those to the Myc epitope from Cell Signaling (Boston, MA, USA). Antibodies to $\mathrm{Arg}^{78}$-methylated ASK1 or to $\mathrm{Arg}^{80}$-methylated ASK1 were generated by injection of rabbits or rats, respectively, with a methylated peptide (SSATRGRGSSVGG or SSATRGRGSSVGG, respectively, corresponding to residues 74 to 86 of human ASK1 and with the underlined arginines being asymmetrically dimethylated) conjugated to keyhole limpet hemocyanin. The resulting antibodies were purified by two-step affinity chromatography. The rabbit or rat antiserum was thus passed over agarose resin coupled with the unmodified peptide, and the resulting flow-through fraction was then subjected to affinity purification with agarose resin coupled with the corresponding methylated peptide immunogen. The specificity of the affinity-purified antibodies was confirmed (Supplementary Figure S2).

DNA constructs. pGEX-PRMT1 and PCMX-PL2-CARM1(PRMT4) vectors were provided by H. Hershmann (UCLA, Los Angeles, CA, USA) and R. M. Evans (Salk Institutes, San Diego, CA, USA), respectively. CARM1 cDNA was subcloned into the EcoRI and Notl sites of pCMV2-FLAG (Sigma). pCMV2-FLAG-PRMT1 and pCMV2-FLAG-PRMT5 were provided by Dongsu Lim (KRIBB, Daejon, Korea). Human thioredoxin 1 CDNA was generated by PCR and subcloned into the BamHI and Notl sites of pEF-HA, a mammalian expression vector for HA-tagged proteins.
The cDNAs for ASK1(1-136) and ASK1(137-656) deletion mutants were amplified by PCR and subcloned into pGEX4T-1 (Amersham Biosciences, Piscataway, NJ, USA) for expression of GST fusion proteins in Escherichia coli. The cDNA for ASK1(1-656) was also amplified by PCR and subcloned into pET-28-a (Novagen, Madison, WI, USA) for expression of the His ${ }_{6}$-tagged protein in E. coli. pGEX4T-1TRAF2, pGEX4T-1-ASK1 (656-1001), pGEX4T-1-ASK1 (1014-1374), and mammalian plasmid vectors encoding Myc epitope-tagged ASK1, HA-ASK1 (1-656), Flag-ASK1(1-656), or Flag-TRAF2 were described previously. ${ }^{12,13,36}$

Site-directed mutagenesis. Site-directed mutagenesis was performed by PCR with the use of a QuickChange kit (Stratagene, La Jolla, CA, USA). The arginine mutants of ASK1 were constructed with the following mutagenic primers: R32K, 5'-GGCATCTGCAGGAAGGGAGGAGCGGCG-3'; R78K, 5'-GAGCAGTG CCACCAAAGGCCGGGGCA $\overline{G C-3}$; R80K, 5'-GCCACCCGAGGCAAGGGCAGC TCTGTTG-3'; and R78K/R80K, 5'-CGAGCAGTGCCACCAAAGGCAAGGGCA GCTCTGTTGGC-3' (mismatches with the template are underlined). The PRMT1(G80R) mutant was constructed with the primer $5^{\prime}$-GATGTGGGCTC GCGCACTGGCATCCTC-3'. All mutations were verified by automatic DNA sequencing.

RNAi. Annealed oligonucleotides corresponding to the target sequences for human PRMT1 mRNA (sense: 5'-GCGAGGAGATCTTCGGCACCA-3') or GFP mRNA (sense: 5'-GGCTACGTCCAGGAGCGCACC-3') were cloned into the pSuper-retro vector (OligoEngine, Seattle, WA, USA). HeLa and MDA-MB-231 cells were transfected with the resulting vectors, and stable transfectants were selected with puromycin $(0.3 \mu \mathrm{g} / \mathrm{ml})$. The siRNA oligonucleotides specific for human PRMT1 (5'-GACGGGCGAGGAGAUCUUC-3'), human ASK1 (5'-GCACUCCUUCAUC GAGCUA-3'), or GFP (5'-GGCUACGUCCAGGAGCGCA-3') mRNAs were obtained from Invitrogen and introduced into cells by transient transfection with the use of a Microporator (Invitrogen).

Co-immunoprecipitation. Cultured cells were lysed with buffer $\mathrm{A}(20 \mathrm{mM}$ Tris- $\mathrm{HCl}, \mathrm{pH} 7.4,150 \mathrm{mM} \mathrm{NaCl}, 1 \%$ Triton X-100, 0.5\% sodium deoxycholate, $12 \mathrm{mM}$ glycerophosphate, $10 \mathrm{mM}$ sodium fluoride, $5 \mathrm{mM}$ EGTA, $2 \mathrm{mM}$ sodium vanadate, $1 \mathrm{mM}$ phenylmethylsulfonyl fluroride, $2 \mu \mathrm{g} / \mathrm{ml}$ aprotinin, and $2 \mu \mathrm{g} / \mathrm{ml}$ leupeptin). Cell lyastes were centrifuged at $12000 \times g$ for $20 \mathrm{~min}$ at $4^{\circ} \mathrm{C}$. The resulting supernatants were subjected to immunoprecipitation with the indicated antibodies, and the immunoprecipitates were washed three times with buffer $A$ and subjected to immunoblot analysis.

Immune complex kinse assay. Assays of protein kinase activity were performed as described previously. ${ }^{37,38}$ In brief, cell lysates were subjected to immunoprecipitation with the indicated antibodies, and the resulting immunoprecipitates were assayed for protein kinase activity with the use of appropriate GST fusion proteins as substrates. The reaction mixtures were subjected to SDS-PAGE, and the extent of substrate phosphorylation was quantified with a Fuji BAS 2500 phosphoimager (Kanagawa, Japan).

In vitro methylation assay. Lysates of $293 \mathrm{~T}$ cells transfected with expression vectors for the indicated Flag-tagged PRMT proteins were subjected to immunoprecipitation with anti-Flag antibody. The immunoprecipiates or bacterially expressed and purified GST-PRMT1 $(1 \mu \mathrm{g})$ were incubated for $1 \mathrm{~h}$ at $30^{\circ} \mathrm{C}$ with the indicated substrates $(1$ to $2 \mu \mathrm{g})$ and $2.2 \mu \mathrm{Ci}$ of S-adenosyl-L-[methyl- $\left.{ }^{3} \mathrm{H}\right]$ methionine (PerkinEImer Life Sciences, Waltham, MA, USA) in $40 \mu$ l of a reaction mixture containing $20 \mathrm{mM}$ Tris- $\mathrm{HCl}$, pH 8.0, $150 \mathrm{mM} \mathrm{NaCl}, 0.4 \mathrm{mM}$ EDTA. The reaction was terminated by the addition of SDS sample buffer, and the reaction mixtures were subjected to SDS-PAGE. Gels were stained with Coomassie brilliant blue for $30 \mathrm{~min}$, destained, soaked in Amplify solution (PerkinElmer Life Sciences) for $30 \mathrm{~min}$, dried, and exposed to HyperFilm MP (Pharmacia, Piscataway, NJ, USA) at $-80^{\circ} \mathrm{C}$ for 1 week.

In vitro binding assay. The reduced form of thioredoxin 1 (Ab Frontier) was prepared as previously described. ${ }^{15}$ Flag-PRMT1 was immunoprecipitated from lysates of transfected 293T cells with anti-Flag antibody. His 6 -tagged ASK1(1-656) was expressed in and purified from E. coli. His $_{6}$-ASK1(1-656) was incubated for $2 \mathrm{~h}$ at $30^{\circ} \mathrm{C}$ without or with Flag-PRMT1 in the presence of S-adenosyl-L-methionine $(1 \mathrm{mM})$. The reaction mixture was subjected to centrifugation at $8000 \times g$ for $1 \mathrm{~min}$ and the supernatant that contained $\mathrm{His}_{6}$-ASK1(1-656) was obtained. The recovered $\mathrm{His}_{6}$-ASK1(1-656) was incubated overnight with the reduced form of thioredoxin 1 or 
GST-TRAF2 in in-vitro binding buffer $(50 \mathrm{mM}$ Tris- $\mathrm{HCl}, \mathrm{pH} 7.5,150 \mathrm{mM} \mathrm{NaCl}, 2 \mathrm{mM}$ EDTA, $0.1 \% \mathrm{NP}-40$ and $5 \mathrm{mg} / \mathrm{ml}$ bovine serum albumin). The binding complexes were isolated with the use of Ni-NTA beads (Qiagen, Hilden, Germany), which were then washed three times with a washing buffer containing 50 mM HEPES, pH 7.5 $150 \mathrm{mM} \mathrm{NaCl}, 1 \mathrm{mM}$ EDTA and $0.1 \%$ Tween 20. Bead-bound proteins were released and then subjected to immunoblot analysis with antibodies to thioredoxin 1 or to TRAF2, as appropriate.

Peptide pull-down assay. Two 13-amino acid peptides (unmethylated and asymmetrically dimethylated at arginine residues) corresponding to residues 74 to 86 (SSATR ${ }^{78} \mathrm{GR}^{80} \mathrm{GSSVGG)}$ of ASK1 were synthesized and biotinylated by Peptron (Daejon, Korea). A peptide pull-down assay was performed as described. ${ }^{39}$ In brief, biotin-labeled peptides $(5 \mu \mathrm{g})$ were incubated overnight at $4^{\circ} \mathrm{C}$ with $25 \mu \mathrm{l}$ of streptavidin-Sepharose beads (GE Healthcare, Piscataway, NJ, USA) in a binding buffer $(50 \mathrm{mM}$ Tris- $\mathrm{HCl}, \mathrm{pH} 7.5,150 \mathrm{mM} \mathrm{NaCl}, 1 \mathrm{mM}$ EDTA, $2 \mathrm{mM}$ DTT, $0.5 \%$ Nonidet P-40), and the beads were then washed three times with the same binding buffer before incubation overnight at $4^{\circ} \mathrm{C}$ with recombinant thioredoxin $1(1.5 \mu \mathrm{g})$ in $0.5 \mathrm{ml}$ of binding buffer. The beads were washed extensively, and the bead-bound material was subjected to immunoblot analysis with antibodies to thioredoxin 1.

Apoptosis assay. MDA-MB-231 cells were transfected for $48 \mathrm{~h}$ with GFP, ASK1, or PRMT1 siRNAs and then incubated for $48 \mathrm{~h}$ with either $0.1 \%$. DMSO or paclitaxel at $1 \mu \mathrm{g} / \mathrm{ml}$. The cells were then fixed with $70 \%$ ethanol, treated with RNase A $(100 \mu \mathrm{g} / \mathrm{ml})$ for $1 \mathrm{~h}$, stained with propidium iodide $(50 \mu \mathrm{g} / \mathrm{ml})$, and analyzed with a flow cytometer (FacsCalibur, Becton Dickinson) and CellQuest software (BD Biosciences, San Diego, CA, USA) for the proportion of cells with a DNA content less than the GOG1 peak. Alternatively, T47D cells transfected for $48 \mathrm{~h}$ with a vector for GFP without or with vectors for the indicated proteins were incubated for $48 \mathrm{~h}$ with $0.1 \%$ DMSO or paclitaxel $(1 \mu \mathrm{g} / \mathrm{ml})$. The cells were then fixed in $3.7 \%$ paraformaldehyde and stained with $4^{\prime}, 6^{\prime}$-diamidino-2-phenylindole dihydrochloride (DAPI). The DAPI-stained nuclei in GFP-positive cells were then examined for apoptotic morphology with a fluorescence microscopy (Axiovert 200, Zeiss, Oberkochen, Germany).

Immunofluorescence analysis. HeLa cells grown on glass coverslips in 6-well plates were transfected for $48 \mathrm{~h}$ with the indicated plasmid vectors, fixed with $3.7 \%$. paraformaldehyde for $30 \mathrm{~min}$, permeabilized with $0.2 \%$ Triton X-100 for $5 \mathrm{~min}$, and blocked with $2 \%$ bovine serum albumin for $1 \mathrm{~h}$ before incubation overnight at $4^{\circ} \mathrm{C}$ with antibodies to Myc and to $\mathrm{Arg}^{78}$-methylated ASK1. They were then incubated with Alexa Fluor 488- or Alexa Fluor 568-labeled secondary antibodies (Molecular Probes, Carlsbad, CA, USA) and DAPI before examination by confocal microscopy (LSM 510 META, Zeiss).

Cell viability assay. Cell viability was measured by 3-(4,5-dimethylthiazol-2yl)-2,5-diphenyltetrazolium bromide (MTT) assay. Cells in 96-well culture dishes (2000 cells per well) were incubated for $48 \mathrm{~h}$ in the presence of $0.1 \%$ DMSO or indicated concentrations of paclitaxel and then incubated further in the presence of MTT $(0.5 \mathrm{mg} / \mathrm{ml})$ for $2 \mathrm{~h}$ at $37^{\circ} \mathrm{C}$. After the incubation, culture medium of each well was discarded and $100 \mu \mathrm{lDMSO}$ was added to dissolve the MTT-formazan crystals. Cell viability was determined by measuring the absorbance at $550 \mathrm{~nm}$ for each well with the use of a microplate reader (iMark, Bio-Rad, Hercules, CA, USA).

Clonal growth assay. Cells in 96-well culture dishes (2000 cells per well) were incubated for $2 \mathrm{~h}$ in the presence of $0.1 \%$. DMSO or indicated concentrations of paclitaxel. Cells were then incubated for an additional 14 days, fixed with $3.7 \%$ paraformaldehyde, and stained with $0.5 \%$ crystal violet in $20 \%$ methanol.

\section{Conflict of interest}

The authors declare no conflict of interest.

Acknowledgements. We thank Drs. H Ichijo for ASK1, RJ Davis for JNK1, H Hershmann for PRMT1, RM Evans for CARM1 and D Lim for PRMT5. This study was supported by a grant from the Korea Healthcare technology R\&D Project, Ministry for Health, Welfare \& Family Affairs, Republic of Korea (A090536) (E-JC).

1. Takeda K, Noguchi T, Naguro I, Ichijo H. Apoptosis signal-regulating kinase 1 in stress and immune response. Annu Rev Pharmacol Toxicol 2008; 48: 199-225.
2. Matsuzawa A, Ichijo $\mathrm{H}$. Redox control of cell fate by MAP kinase: physiological roles of ASK1-MAP kinase pathway in stress signaling. Biochim Biophys Acta 2008; 1780: 1325-1336.

3. Hatai T, Matsuzawa A, Inoshita S, Mochida Y, Kuroda T, Sakamaki K et al. Execution of apoptosis signal-regulating kinase 1 (ASK1)-induced apoptosis by the mitochondriadependent caspase activation. J Biol Chem 2000; 275: 26576-26581.

4. Tobiume K, Matsuzawa A, Takahashi T, Nishitoh H, Morita K, Takeda K et al. ASK1 is required for sustained activations of JNK/p38 MAP kinases and apoptosis. EMBO Rep 2001; 2: 222-228.

5. Ichijo H, Nishida E, Irie K, ten Dijke P, Saitoh M, Moriguchi T et al. Induction of apoptosis by ASK1, a mammalian MAPKKK that activates SAPK/JNK and p38 signaling pathways. Science 1997; 275: 90-94.

6. Kim AH, Khursigara G, Sun X, Franke TF, Chao MV. Akt phosphorylates and negatively regulates apoptosis signal-regulating kinase 1. Mol Cell Biol 2001; 21: 893-901.

7. Yuan ZQ, Feldman RI, Sussman GE, Coppola D, Nicosia SV, Cheng JQ. AKT2 inhibition of cisplatin-induced JNK/p38 and Bax activation by phosphorylation of ASK1: implication of AKT2 in chemoresistance. J Biol Chem 2003; 278: 23432-23440.

8. Park HS, Yu JW, Cho JH, Kim MS, Huh SH, Ryoo K et al. Inhibition of apoptosis signalregulating kinase 1 by nitric oxide through a thiol redox mechanism. J Biol Chem 2004; 279: 7584-7590.

9. Chang HY, Nishitoh H, Yang X, Ichijo H, Baltimore D. Activation of apoptosis signalregulating kinase 1 (ASK1) by the adapter protein Daxx. Science 1998; 281: 1860-1863.

10. Park HS, Cho SG, Kim CK, Hwang HS, Noh KT, Kim MS et al. Heat shock protein hsp72 is a negative regulator of apoptosis signal-regulating kinase 1. Mol Cell Biol 2002; 22: 7721-7730.

11. Asada M, Yamada T, Ichijo H, Delia D, Miyazono K, Fukumuro K et al. Apoptosis inhibitory activity of cytoplasmic p21(Cip1/WAF1) in monocytic differentiation. EMBO J 1999; 18: 1223-1234.

12. Cho SG, Lee YH, Park HS, Ryoo K, Kang KW, Park J et al. Glutathione S-transferase mu modulates the stress-activated signals by suppressing apoptosis signal-regulating kinase 1. J Biol Chem 2001; 276: 12749-12755.

13. Cho SG, Kim JW, Lee YH, Hwang HS, Kim MS, Ryoo K et al. Identification of a novel antiapoptotic protein that antagonizes ASK1 and CAD activities. J Cell Biol2003; 163: 71-81.

14. Zhang R, He X, Liu W, Lu M, Hsieh JT, Min W. AIP1 mediates TNF-alpha-induced ASK1 activation by facilitating dissociation of ASK1 from its inhibitor 14-3-3. J Clin Invest 2003; 111: 1933-1943.

15. Saitoh M, Nishitoh H, Fujii M, Takeda K, Tobiume K, Sawada $Y$ et al. Mammalian thioredoxin is a direct inhibitor of apoptosis signal-regulating kinase (ASK) 1. EMBO J 1998; 17: 2596-2606.

16. Noguchi T, Takeda K, Matsuzawa A, Saegusa K, Nakano H, Gohda J et al. Recruitment of tumor necrosis factor receptor-associated factor family proteins to apoptosis signalregulating kinase 1 signalosome is essential for oxidative stress-induced cell death. $\mathrm{J} \mathrm{Biol}$ Chem 2005; 280: 37033-37040.

17. Tobiume K, Saitoh M, Ichijo H. Activation of apoptosis signal-regulating kinase 1 by the stress-induced activating phosphorylation of pre-formed oligomer. J Cell Physiol 2002; 191: 95-104.

18. Fujino G, Noguchi T, Matsuzawa A, Yamauchi S, Saitoh M, Takeda K et al. Thioredoxin and TRAF family proteins regulate reactive oxygen species-dependent activation of ASK1 through reciprocal modulation of the N-terminal homophilic interaction of ASK1. Mol Cell Biol 2007; 27: 8152-8163.

19. Bedford MT, Richard S. Arginine methylation an emerging regulator of protein function. Mol Cell 2005; 18: 263-272.

20. Boisvert FM, Chenard CA, Richard $S$. Protein interfaces in signaling regulated by arginine methylation. Sci STKE 2005; 2005: re2.

21. McBride AE, Silver PA. State of the arg: protein methylation at arginine comes of age. Cell 2001; 106: 5-8

22. Bedford MT, Clarke SG. Protein arginine methylation in mammals: who, what, and why. $\mathrm{Mol}$ Cell 2009; 33: 1-13.

23. Lin WJ, Gary JD, Yang MC, Clarke S, Herschman HR. The mammalian immediate-early TIS21 protein and the leukemia-associated BTG1 protein interact with a protein-arginine N-methyltransferase. J Biol Chem 1996; 271: 15034-15044

24. Tang J, Frankel A, Cook RJ, Kim S, Paik WK, Williams KR et al. PRMT1 is the predominant type I protein arginine methyltransferase in mammalian cells. J Biol Chem 2000; 275: 7723-7730.

25. Pawlak MR, Scherer CA, Chen J, Roshon MJ, Ruley HE. Arginine N-methyltransferase 1 is required for early postimplantation mouse development, but cells deficient in the enzyme are viable. Mol Cell Biol 2000; 20: 4859-4869.

26. Liu $\mathrm{H}$, Nishitoh $\mathrm{H}$, Ichijo $\mathrm{H}$, Kyriakis JM. Activation of apoptosis signal-regulating kinase 1 (ASK1) by tumor necrosis factor receptor-associated factor 2 requires prior dissociation of the ASK1 inhibitor thioredoxin. Mol Cell Biol 2000; 20: 2198-2208.

27. Wang TH, Wang HS, Ichijo H, Giannakakou P, Foster JS, Fojo $T$ et al. Microtubuleinterfering agents activate c-Jun $\mathrm{N}$-terminal kinase/stress-activated protein kinase through both Ras and apoptosis signal-regulating kinase pathways. J Biol Chem 1998; 273: 4928-4936.

28. Yamagata K, Daitoku H, Takahashi Y, Namiki K, Hisatake K, Kako K et al. Arginine methylation of FOXO transcription factors inhibits their phosphorylation by Akt. Mol Cell 2008; 32: 221-231. 
29. Le Romancer M, Treilleux I, Leconte N, Robin-Lespinasse Y, Sentis S, BouchekiouaBouzaghou $\mathrm{K}$ et al. Regulation of estrogen rapid signaling through arginine methylation by PRMT1. Mol Cell 2008; 31: 212-221.

30. Goulet I, Gauvin G, Boisvenue S, Cote J. Alternative splicing yields protein arginine methyltransferase 1 isoforms with distinct activity, substrate specificity, and subcellular localization. J Biol Chem 2007; 282: 33009-33021.

31. Papadokostopoulou A, Mathioudaki K, Scorilas A, Xynopoulos D, Ardavanis A, Kouroumalis $\mathrm{E}$ et al. Colon cancer and protein arginine methyltransferase 1 gene expression. Anticancer Res 2009; 29: 1361-1366.

32. Cheung N, Chan LC, Thompson A, Cleary ML, So CW. Protein arginine-methyltransferasedependent oncogenesis. Nat Cell Biol 2007; 9: 1208-1215.

33. Yoshimatsu M, Toyokawa G, Hayami S, Unoki M, Tsunoda T, Field HI et al. Dysregulation of PRMT1 and PRMT6, Type I arginine methyltransferases, is involved in various types of human cancers. Int J Cancer 2011; 128: 562-573.
34. Mathioudaki K, Scorilas A, Ardavanis A, Lymberi P, Tsiambas E, Devetzi M et al. Clinical evaluation of PRMT1 gene expression in breast cancer. Tumour Biol 2011; 32: 575-582.

35. Chen Z, Seimiya H, Naito M, Mashima T, Kizaki A, Dan S et al. ASK1 mediates apoptotic cell death induced by genotoxic stress. Oncogene 1999; 18: 173-180.

36. Kim EK, Noh KT, Yoon JH, Cho JH, Yoon KW, Dreyfuss G et al. Positive regulation of ASK1-mediated c-Jun $\mathrm{NH}(2)$-terminal kinase signaling pathway by the WD-repeat protein Gemin5. Cell Death Differ 2007; 14: 1518-1528.

37. Park HS, Lee JS, Huh SH, Seo JS, Choi EJ. Hsp72 functions as a natural inhibitory protein of c-Jun N-terminal kinase. EMBO J 2001; 20: 446-456.

38. Ryoo K, Huh SH, Lee YH, Yoon KW, Cho SG, Choi EJ. Negative regulation of MEKK1-induced signaling by glutathione S-transferase Mu. J Biol Chem 2004; 279 43589-43594.

39. Lee YH, Bedford MT, Stallcup MR. Regulated recruitment of tumor suppressor BRCA1 to the p21 gene by coactivator methylation. Genes Dev 2011; 25: 176-188.

Supplementary Information accompanies the paper on Cell Death and Differentiation website (http://www.nature.com/cdd) 